\title{
Biomechanical Comparison of the Track Start and the Modified One-Handed Track Start in Competitive Swimming: An Intervention Study
}

\author{
H. Galbraith, ${ }^{1}$ J. Scurr, ${ }^{1}$ C. Hencken, ${ }^{1}$ L. Wood, ${ }^{1}$ and P. Graham-Smith ${ }^{2}$ \\ ${ }^{1}$ University of Portsmouth and ${ }^{2}$ University of Salford
}

This study compared the conventional track and a new one-handed track start in elite age group swimmers to determine if the new technique had biomechanical implications on dive performance. Five male and seven female GB national qualifiers participated (mean $\pm S D$ : age $16.7 \pm 1.9$ years, stretched stature $1.76 \pm$ $0.8 \mathrm{~m}$, body mass $67.4 \pm 7.9 \mathrm{~kg}$ ) and were assigned to a control group $(n=6)$ or an intervention group $(n=6)$ that learned the new onehanded dive technique. All swimmers underwent a 4-week intervention comprising $12 \pm 3$ thirty-minute training sessions. Video cameras synchronized with an audible signal and timing suite captured temporal and kinematic data. A portable force plate and load cell handrail mounted to a swim starting block collected force data over 3 trials of each technique. A MANCOVA identified Block Time (BT), Flight Time (FT), Peak Horizontal Force of the lower limbs (PHF) and Horizontal Velocity at Take-off ( $\mathrm{Vx})$ as covariates. During the 10-m swim trial, significant differences were found in Time to $10 \mathrm{~m}$ (TT10m), Total Time (TT), Peak Vertical Force (PVF), Flight Distance (FD), and Horizontal Velocity at Take-off (Vx) $(p<.05)$. Results indicated that the conventional track start method was faster over $10 \mathrm{~m}$, and therefore may be seen as a superior start after a short intervention. During training, swimmers and coaches should focus on the most statistically significant dive performance variables: peak horizontal force and velocity at take-off, block and flight time.

Galbraith, Scurr, Hencken, and Wood are with the Department of Sport and Exercise Science, University of Portsmouth, Portsmouth, U.K., and Graham-Smith is with Centre for Rehabilitation and Human Performance Research, University of Salford, Greater Manchester, U.K.
Keywords: diving, force platform, kinematics, kinetics

In competitive swimming, the fundamental goal is to cover a set distance in the least amount of time. When evaluating a swimmer's performance, several measures are considered including final time, strategy, and technical components. The latter includes speed, stroke mechanics, starting, turning, and finishing (Smith et al., 2002). Emphasis during training is often placed on high mileage, speed work, and stroke drills, leaving very little time for perfecting the starting technique (Maglischo, 2003). The start is an area where small yet significant gains can be made. Researchers have found that through consistent dive practice an elite swimmer can reduce their total race time by a minimum of $0.10 \mathrm{~s}$ (Blanksby et al., 2002; Maglischo, 2003). At the elite level, this improvement could represent the time difference between a first and third place in a sprint event (Thayer \& Hay, 1984; Cossor et al., 1999; Breed \& McElroy, 2000; Breed \& Young, 2003; Lyttle \& Benjanuvatra, 2005).

As cited by Lyttle \& Benjanuvatra (2005), the three main starting techniques currently used by elite swimmers include the track start (both rear and front weighted), the grab start, and the swing start (mainly used during relays). It has been suggested that neither preference nor experience is a good indicator of the best dive style for a swimmer and guided experimentation may be most beneficial (Welcher et al., 1999). The findings to date have shown that regardless of swim start choice, the swimmer's goal is to react quickly to the starting signal, leave the blocks rapidly generating as much horizontal velocity as possible, gain maximal flight distance while using an optimal projection angle on entry, and maintain a streamline position that will minimize the loss of horizontal velocity associated with drag on water entry (Pearson et al., 1998).

Over the last 40 years, the swim start technique has evolved. The original arm swing diving technique was 
used consistently up to the late 1960s, but was later replaced by the grab start (Carlile, 1963; Colwin, 1969; Counsilman, 1985). Introduced by Hanauer in 1967, the grab start rapidly gained popularity and by the 1972 Olympics, most swimmers were using a variation of the technique (Nelson \& Pike, 1978; Counsilman et al., 1988) and it remains a widely used technique today (Pearson et al., 1998). When compared with the conventional swing start, most researchers have found the grab start superior in terms of timed distances and time spent on the block (Bowers \& Cavanagh, 1975; Zatsiorsky et al., 1979).

The track start debuted in the late 1970s; both the rear- and front-weighted track starts have gained popularity and proven successful on the international competition scene (Lyttle \& Benjanuvatra, 2005). The track start is reported as equivalent to the grab start due to trade-offs in increased take-off velocity and reduced block time (grab; Costill et al.,1992; Allen et al., 1999), yet others have found the track start superior to the grab start when solely comparing performance times (Ayalon et al., 1975; Zatsiorsky et al., 1979; Counsilman et al., 1988; Kruger et al., 2002). Due to changes in the swimmer's foot placement, the track start employs a wider base of support than the grab start resulting in greater stability for the swimmer (Breed \& McElroy, 2000).

Recent anecdotal evidence of a one-handed track method used by swimmers in the UK and Japan suggested that modifications made to the traditional track start could be beneficial for biomechanical reasons due to the incorporation of both a grab and a counter-movement swing.

The effectiveness of dive starts has been measured by the time to a set distance, ranging from $1.52 \mathrm{~m}(5 \mathrm{ft})$ to $25 \mathrm{~m}$ (Ayalon et al., 1975; Bowers \& Cavanagh, 1975; Stevenson \& Moorehouse, 1979; Guimaraes \& Hay, 1985; Counsilman et al., 1988; Blanksby et al., 2002). However, recent findings using elite subjects have demonstrated that the best criterion measure of swim start performance is time to $10 \mathrm{~m}$ (Blitvich et al., 2000; McLean et al., 2000; Blanksby et al., 2002). Havriluk (1983) found that subjects attain a constant velocity during the 8.7 - to $11.7-\mathrm{m}$ interval. Block time, flight time, and glide time are included in this $10 \mathrm{~m}$, but the effects of other swim variables on performance are eliminated.

Force characteristics of dive techniques have been assessed in several comparison studies including the swing, grab, track, and handle starts (Shierman, 1979; Pearson et al., 1998; Allen et al., 1999; Breed \& McElroy, 2000; Breed \& Young, 2003). Breed \& McElroy (2000) found a significant difference between the horizontal impulse of the track and grab start $(p<.05)$ but not between the swing or grab, nor the track and swing starts. When separating the force contribution from the hands and feet, Breed \& McElroy (2000) also discovered that the arms in the grab start acted as a brace for the legs to push against (mean $6.4 \pm 10.9 \mathrm{~N} \cdot \mathrm{s}$ ) and that almost all of the drive came from the lower limbs (mean $174 \pm 19.0 \mathrm{~N} \cdot \mathrm{s}$ ). Conversely, the contribution of the arms in the track start was much more significant (mean $70.2 \pm 27.4 \mathrm{~N} \cdot \mathrm{s}$ ) and represented one-third of the total horizontal impulse. In addition, Breed and McElroy (2000) found that the rear-weighted dive produced a greater take-off velocity and flight distance than the grab and front weighted track technique and attributed this to the increased force contribution of the upper limbs in the track start.

A major limitation in the research to date is the use of nonswimmers, who lack the required skill and coordination to perform the complex racing start movements and have very little dive experience (Guimaraes \& Hay, 1985; Ayalon et al., 1975; Breed \& McElroy, 2000; Breed \& Young, 2003). For the results to apply convincingly to the elite population, there is a need to use proficient swimmers who can perform consistently (Pearson et al., 1998; Hopkins et al., 1999).

The purpose of this study was to compare the track start and one-handed track techniques and to assess dive performance in age group elites. A one-handed track start was developed, where the lower limb stance remained identical to the conventional technique but the upper body was rotated and a one-arm countermovement swing was used: No previous research used this technique. This study hypothesized that, following an intervention, the modified start would significantly affect the kinematics and kinetics of a dive start when compared with the track start in elite swimmers and, further, swimmers would elicit faster times over $10 \mathrm{~m}$ when using the conventional track method.

\section{Methods}

\section{Subjects}

Seven female and five male age group Great Britain National qualifiers of a mean $\pm S D$ age of $16.7 \pm 1.9$ years, stretched stature $1.76 \pm 0.8 \mathrm{~m}$, and body mass $67.4 \pm 7.9 \mathrm{~kg}$, participated in the study. No significant changes in mass or stature occurred during the study ( $p$ $>$.05). Participants had been involved in competitive swimming for $8.5 \pm 2.0$ years and their career-best $50-\mathrm{m}$ freestyle (long course) was $27.41 \pm 3.0 \mathrm{~s}$. The preferred starting method of all swimmers was the track start technique. The institutional ethics committee approved all procedures and informed consent and assent was gained from both parents and children, respectively, before data collection.

\section{Initial Testing Procedure}

All swimmers performed 8 trials of their preferred competitive dive to assess how many dives would produce repeatable results. Normal competition procedures were followed using a standard starting block $(0.72 \mathrm{~m})$. Time to $10 \mathrm{~m}$ was recorded at the point where the vertex of the 
head crossed the 10-m line, using above water video cameras $(50 \mathrm{~Hz}$, Sony TRV-900-E, shutter speed 800 $\mathrm{Hz}$, and exposure $18 \mathrm{~dB}$ ) synchronized with a video timer box (Omega, British Swimming, 2002) and DV recorder (Sony, GVD-1000 E DV) with a time code display and an audible starting signal (Lakomy, British Swimming, 2002). Within-athlete reliability was achieved, as the coefficient of variance was less than 5\% (2.2\%) using time to $10 \mathrm{~m}$ over the first 3 dive trials.

Using rank order over 2 variables (career-best 50-m freestyle time and initial testing track start time), groups of equal performance ability were assigned to respective cohorts (control group or intervention group). The onehanded technique was explained to the intervention group and they performed an additional 8 trials of the new technique: A coefficient of variance of less than 5\% (3.2\%) was obtained over the first 3 dive trials.

\section{Training Procedure}

A 4-week intervention period of $12 \pm 3$ practice sessions of $30 \mathrm{~min}$ in duration was carried out in a 33-m indoor pool. The intervention group learned the new one-handed track start technique (Figure 1). For control purposes, swimmers were instructed to adopt their track start stance (feet $0.40 \mathrm{~m}$ apart) with the toes of one foot curled over the front of the starting block and the other foot placed at the rear of the block. Weight was positioned over the front foot, and the T-bar handrail was grasped as close to the center as possible with their dominant arm while extending their nondominant arm to the rear, past their hip (as per a swing start). The control group did not receive the intervention training but were permitted to practice the track start during the dive training sessions.

The controls were instructed to adopt their track start stance (Figure 2), position their weight over their front foot and grasp the T-bar handrail with both hands. Both groups received verbal and video feedback on their respective diving techniques during Weeks 2 and 3. All dive practice sessions were led by the same coach to ensure consistency in coaching techniques, training, and programming.

\section{Final Testing Procedure}

Following the intervention period, all subjects were tested in a randomized set of 3 dive trials using both start techniques. Testing was conducted after a coachled dry-land warm-up and 10 min pool warm-up. The control group was provided with general instruction in the one-handed track start and 3 practice trials encompassing both techniques were permitted before testing. The rest interval between each dive was 3 min.

A portable multicomponent Kistler force plate with built-in charge amplifier (9286AA, Amherst, New York) sampling $500 \mathrm{~Hz}(600 \mathrm{~mm} \times 400 \mathrm{~mm} \times 35 \mathrm{~mm})$ measured the ground reaction forces. The force plate was

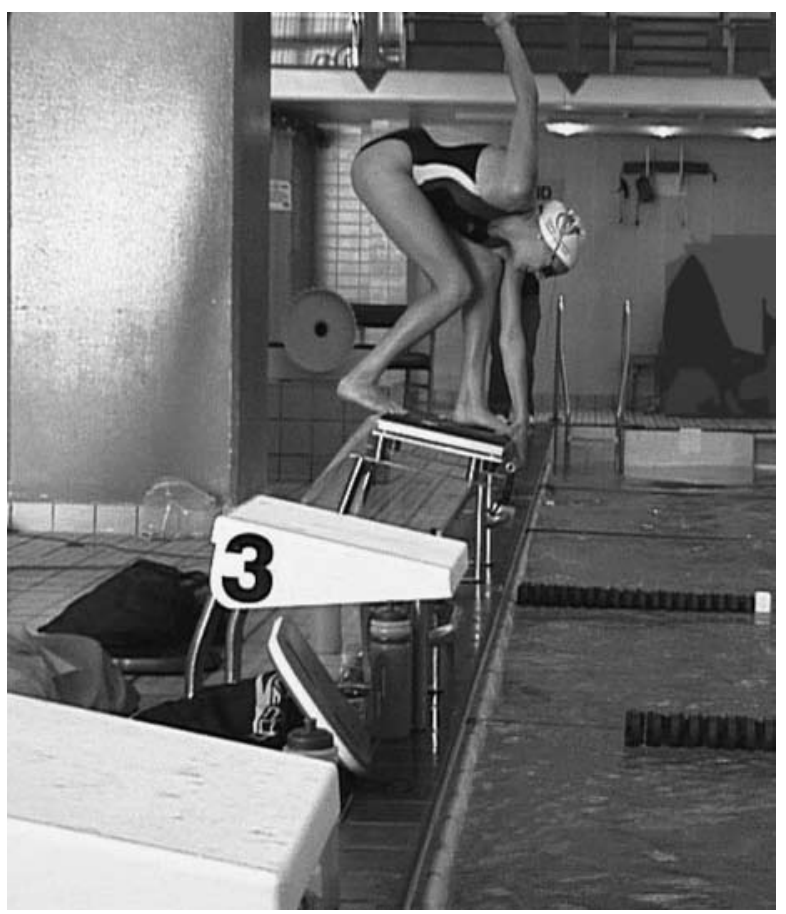

Figure 1 - The one-handed track start.

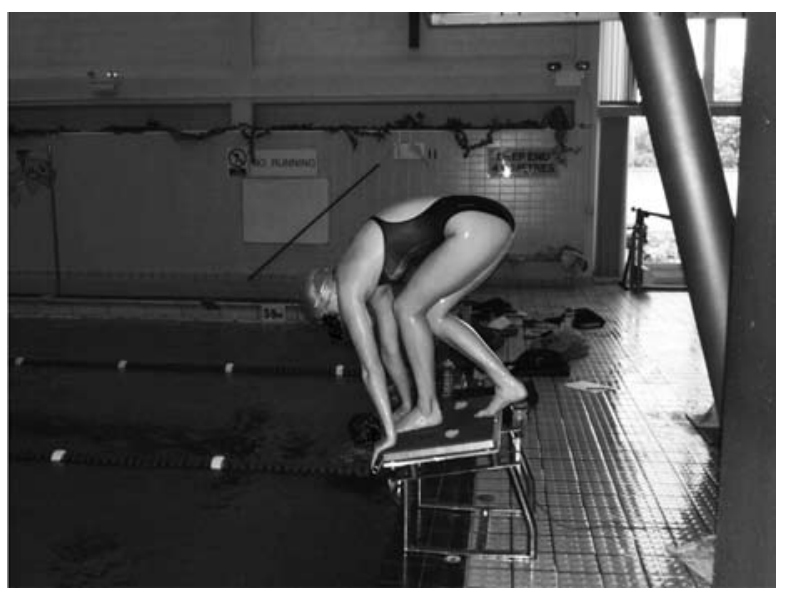

Figure 2 - The track start.

mounted to a $10-\mathrm{mm}$-thick aluminum plate that was bolted to the starting block frame, and the force plate feet were affixed to the aluminum plate. An aluminum T-bar handrail instrumented with a load cell (Biometrics, UK) was affixed to the front of the starting block to measure the force application of the upper limbs (Cavanagh et al., 1975). The load cell was mounted inferiorly to the center of the T-bar handrail to minimize force measurement error during the one-handed track start (Figure 3). The modifications made to starting block did not significantly alter its height, width, or 


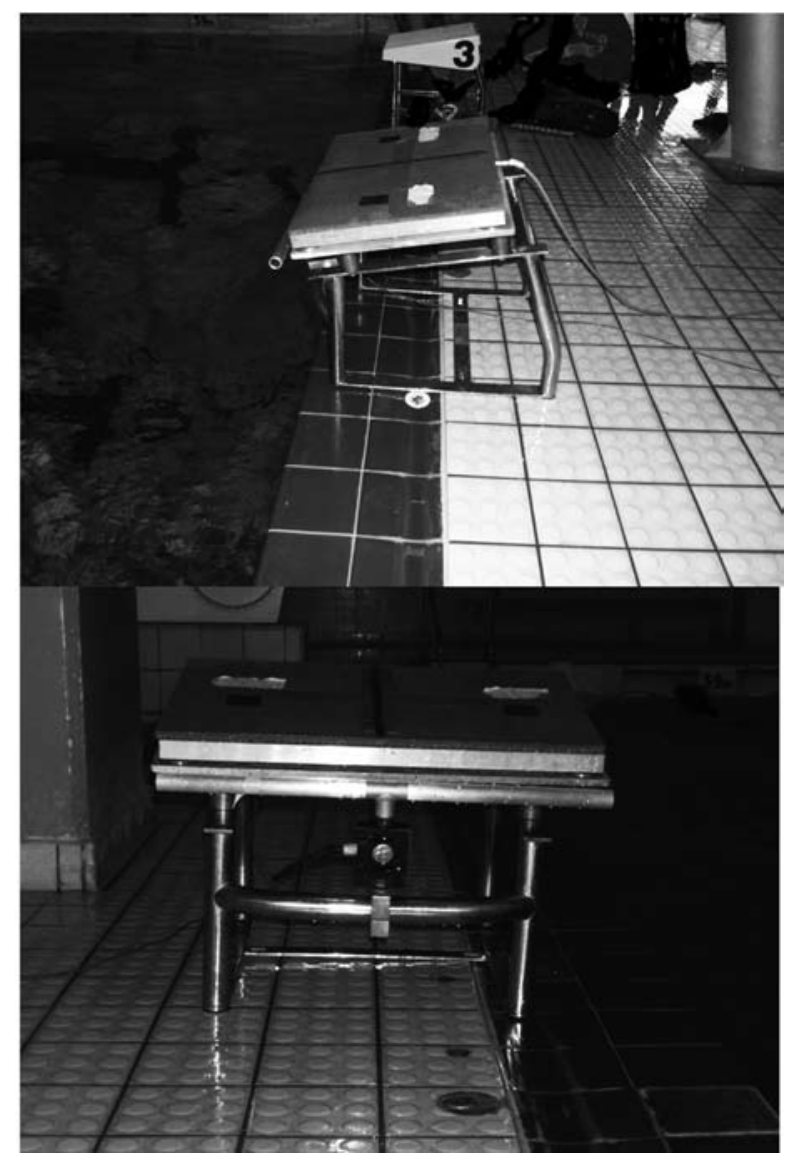

Figure 3 - The modified starting block.

angle. However, due to the dimensions of the force plate, the depth of the starting block was reduced by 7 $\mathrm{cm}$. Force data were analyzed using Bioware version 3.24 (Amherst, New York) and upper limb data were analyzed using Biometrics Datalogger (Biometrics, UK) software.

Two Sony TRV-900-E digital cameras $(50 \mathrm{~Hz}$, shutter speed $800 \mathrm{~Hz}$, and exposure $18 \mathrm{~dB}$ ) were positioned perpendicular to the plane of motion and the starting block. Camera 1 was placed in line with the starting block; Camera 2 was placed on the pool deck $4.5 \mathrm{~m}$ from the starting block wall. Cameras were calibrated vertically and horizontally using a 1-m-long rigid pole with visible markings at $0.1-\mathrm{m}$ increments. Kinematic data were digitized and analyzed using SIMI motion analysis software (SIMI, Germany).

\section{Data Analysis}

Four temporal and two kinematic variables were identified: Block Time (BT) - the time from starting signal until the first field in which the feet had left the blocks; Flight Time (FT) - the time from when the last foot left the block to the first field in which the fingertips broke the water surface; Total Time (TT) - the sum of BT and FT; Time to $10 \mathrm{~m}$ (TT10m); Flight distance (FD) - the horizontal distance from the edge of the pool to fingertip entry; and Take-off angle (TOA) - the angle between a line from the hip to the toes and between the toes and horizontal plane at take-off.

Six variables were measured using the force platform: peak horizontal and vertical force (PHF and PVF respectively) adjusted for body mass, horizontal and vertical velocity at take-off ( $\mathrm{Vx}$ and $\mathrm{Vy}$ respectively), vertical force of the upper limbs (VFH) and horizontal impulse (HI). The vertical and horizontal velocity calculations were derived using the mass of the swimmer and the impulse-momentum relationship, $\left(\mathrm{F}_{\mathrm{t}}=\mathrm{M}_{\mathrm{v} \text { (final) }}\right.$ $-\mathrm{M}_{\mathrm{v} \text { (initial) }}$ ), where impulse equals area under the graph and initial velocity at take-off equals zero. Resulting force data represented the force application through the center of mass.

Force and impulse data were adjusted for body mass. As cited by Breed and McElroy (2000), horizontal impulse (HI) was calculated by adding the hand and feet readings together and the equations $\left(\mathrm{F}_{\mathrm{y}}=\mathrm{F}_{\mathrm{y}} \cos \theta+\right.$ $\left.\mathrm{F}_{\mathrm{z}} \sin \theta\right)$ and $\left(\mathrm{F}_{\mathrm{z}}=-\mathrm{F}_{\mathrm{y}} \sin \theta+\mathrm{F}_{\mathrm{z}} \cos \theta\right)$, where $\mathrm{F}_{\mathrm{y}}$ represents horizontal force and $\mathrm{F}_{\mathrm{z}}$ represents vertical force, were used to adjust the results to give true horizontal and vertical force components due to the $9^{\circ}$ downward slope of the block.

Statistical comparisons were made between the two techniques (3 trials of each) and the two groups. The Kolmogorov-Smirnov test of normality revealed that all data were normally distributed. Assumptions underpinning a MANCOVA were met as linear relationships among the kinetic and kinematic variables were identified; a MANCOVA is particularly useful when one dependent variable impacts on another despite the independent variables being mutually exclusive (SPSS Version 13.0 program for Windows, SPSS, Chicago, IL). An a priori alpha level of 0.05 was set for all data analysis, whereby the statistical significance level was $5 \%$, and alpha represented the probability of rejecting the hypothesis when the hypothesis was true.

\section{Results}

The MANCOVA revealed four covariates: block time, flight time, peak horizontal force of the lower limbs, and vertical velocity at take-off. When controlling for covariance, the MANCOVA ascertained overall significant differences in total time, time to $10 \mathrm{~m}$, peak vertical force (lower limbs), horizontal velocity at take-off, and flight distance between the two diving techniques (Figure 4). The total time and total time to $10 \mathrm{~m}$ were significantly improved when swimmers used the conventional track start: respectively, $F=(359.33,7), p=$ .01 and $F=(6.06,7), p=.001$. Generation of peak vertical force off the blocks, $F=(28.70,7), p=.01$, and peak horizontal velocity, $F=(29.17,7), p=.01$, were also significantly greater when the swimmers used the track start. However, the swimmers achieved significantly better flight distance when they used the one-handed method, which had been previously highlighted as a key 


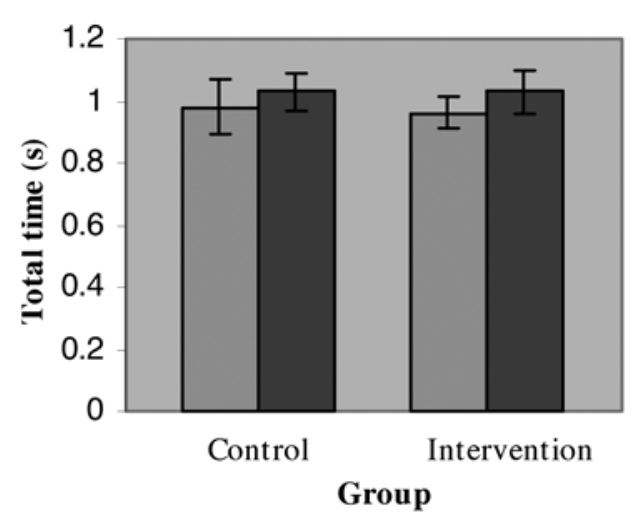

Significance between dive types $(\mathrm{P}=<0.01)$

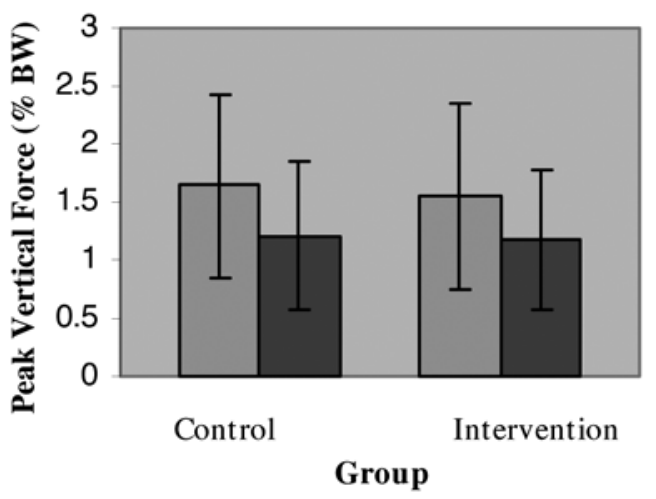

Significance between dive types $(P=0.01)$

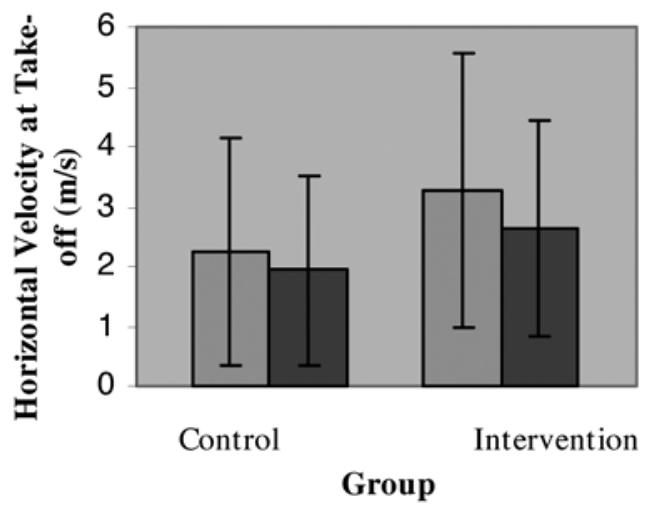

Significance between dive types $(P=0.01)$

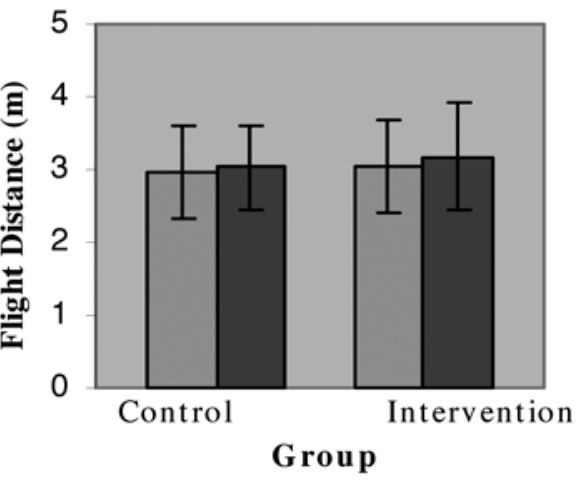

Significance between dive types $(\mathrm{P}=0.004)$

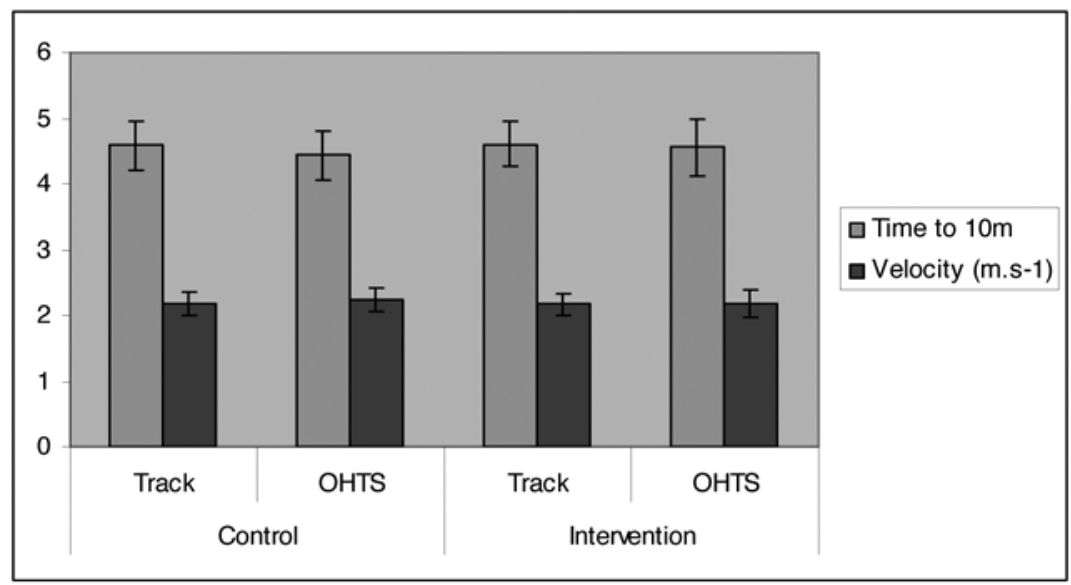

Significance between dive types $(\mathrm{P}=0.001)$

Figure 4 - Means and standard deviations in Total Time, Time to 10m/Velocity, Peak Vertical Force, Flight Distance, and Horizontal Velocity at Take-Off across dive groups and dive types.

factor in successful dive performance $F=(5.07,7), p=$ .003 ; this occurred despite generating less force as a percentage of their body weight and less horizontal velocity off the blocks.
Despite differences in upper-body technique, the MANCOVA revealed similar block time, flight time, take-off angle, peak horizontal force of the lower limbs, vertical velocity at take-off, horizontal impulse, and 
vertical force of the upper limbs when comparing both dive techniques as outlined in Table 1.

In addition, the MANCOVA identified four covariates (block time, flight time, flight time, peak horizontal force of the lower limb, and vertical velocity) that significantly influenced other variables measured as outlined in Table 2. The swimmers' block time and flight time influenced their respective time to $10 \mathrm{~m}$, whereas their peak horizontal force of the lower limbs affected both their time to $10 \mathrm{~m}$ and flight distance.
Lastly, the swimmers' vertical velocity at take-off was found to significantly influence their flight distance.

Significant differences in time to $10 \mathrm{~m}$ were established across the groups $(p=.05)$, and significant differences in peak vertical force of the lower limbs and takeoff angle ( $p=.022$ and $p=.015$, respectively) were found across dive type, but the group and type of dive together did not influence the remaining variables (Table 3).

Table 1 Descriptive Statistics for Tested Variables (Mean $\pm S D$ )

\begin{tabular}{|c|c|c|c|c|}
\hline \multirow[b]{2}{*}{ Variable } & \multicolumn{2}{|c|}{ Control Group } & \multicolumn{2}{|c|}{ Intervention Group } \\
\hline & Track start & $\begin{array}{c}\text { One-handed } \\
\text { track start }\end{array}$ & Track start & $\begin{array}{c}\text { One-handed } \\
\text { track start }\end{array}$ \\
\hline Block Time (s) & $0.66 \pm 0.05$ & $0.70 \pm 0.06$ & $0.67 \pm 0.07$ & $0.69 \pm 0.08$ \\
\hline Flight Time (s) & $0.32 \pm 0.09$ & $0.33 \pm 0.06$ & $0.30 \pm 0.08$ & $0.34 \pm 0.06$ \\
\hline Angle at Take-off $\left(^{\circ}\right)$ & $4.9 \pm 1.9$ & $2.0 \pm 1.9$ & $4.0 \pm 2.3$ & $2.7 \pm 2.2$ \\
\hline Peak Horiz. Force (Lower Limbs; \% BW) & $0.38 \pm 0.06$ & $0.39 \pm 0.60$ & $0.36 \pm 0.08$ & $0.35 \pm 0.08$ \\
\hline Horizontal Impulse $(\mathrm{N} \cdot \mathrm{s})$ & $113.5 \pm 38.2$ & $101.3 \pm 26.7$ & $124.8 \pm 22.6$ & $114.4 \pm 25.0$ \\
\hline Vertical Velocity at Take- off, V(y) (m/s) & $23.1 \pm 19.31$ & $24.6 \pm 20.55$ & $27.3 \pm 22.54$ & $25.7 \pm 23.88$ \\
\hline Peak Vertical Force (Upper Limbs; N) & $41.6 \pm 15.0$ & $32.8 \pm 10.2$ & $38.0 \pm 33.2$ & $25.5 \pm 12.5$ \\
\hline
\end{tabular}

Table 2 Dive Start Variables Influenced by Identified Covariates

\begin{tabular}{|c|c|c|c|c|c|}
\hline \multirow{2}{*}{$\begin{array}{l}\text { Identified } \\
\text { Covariates }\end{array}$} & \multirow[b]{2}{*}{ F Value } & \multirow[b]{2}{*}{$d f$} & \multirow[b]{2}{*}{ Power } & \multicolumn{2}{|c|}{ Variables Influenced } \\
\hline & & & & Kinematic/Temporal & Kinetic \\
\hline \multirow[t]{2}{*}{ Block Time } & 656.79 & 1 & 1.000 & $\mathrm{TT}(p \leq 0.01)$ & \multirow[t]{2}{*}{ N.S. } \\
\hline & 6.57 & 1 & 0.673 & TT10M $(p \leq 0.05)$ & \\
\hline \multirow[t]{2}{*}{ Flight Time } & 454.91 & 1 & 1.000 & $\mathrm{TT}(p \leq 001)$ & \multirow[t]{2}{*}{ N.S. } \\
\hline & 5.39 & 1 & 0.588 & $\mathrm{TT} 10 \mathrm{M}(p \leq 0.05)$ & \\
\hline \multirow{2}{*}{$\begin{array}{l}\text { Peak Horizontal } \\
\text { Force }\end{array}$} & 15.07 & 1 & 0.954 & $\mathrm{TT} 10 \mathrm{M}(p \leq 0.01)$ & \multirow[t]{2}{*}{ N.S. } \\
\hline & 15.02 & 1 & 0.953 & $\operatorname{FD}(p \leq 0.01)$ & \\
\hline \multirow{3}{*}{$\begin{array}{l}\text { Vertical Velocity } \\
\text { at Take-off, V(y) }\end{array}$} & 72.93 & 1 & 1.000 & $\mathrm{FD}(p \leq 0.014)$ & \multirow{3}{*}{$\begin{array}{l}\mathrm{VFF}(p=0.000) \\
\mathrm{V}(\mathrm{x})(p=0.000)\end{array}$} \\
\hline & 98.68 & 1 & 1.000 & & \\
\hline & 7.62 & 1 & 0.736 & & \\
\hline
\end{tabular}

Note. TT $=$ Total Time, TT10M $=$ Time to $10 \mathrm{~m}, \mathrm{FD}=$ Flight Distance, N.S. = No significant difference.

Table 3 Dive Start Variables Influenced by Group, Dive Type, and Combined Group and Dive Type

\begin{tabular}{lcc}
\hline Identified Covariates & Power & Variables Influenced \\
\hline Group Type & 0.489 & TT10M, F $=(4.22,1), p=0.05$ \\
Dive Type & 0.726 & TOA, F $=(1.18,1), p=0.015$ \\
& 0.660 & PVF, F $=(6.37,1), p=0.022)$ \\
Group and Type combined & & N.S. \\
\hline Note. TT10M = Time to $10 \mathrm{~m}$, TOA = Take-off Angle, PVF = Peak Vertical Force, N.S. = No significant difference.
\end{tabular}




\section{Discussion}

This study hypothesized that significant differences would be found in kinetic and kinematic variables between the new one-handed track start and the conventional track start after an intervention period. Results showed significant differences in five variables (time to $10 \mathrm{~m}$, peak vertical force of the lower limbs, horizontal velocity at take-off, flight distance, and total time) and demonstrated that the conventional track start was superior to the new method when considering overall dive performance (time to $10 \mathrm{~m}$ ).

The reported times to $10 \mathrm{~m}$ for both techniques were similar to previous cited findings using elites swimmers performing the grab and track techniques (McLean et al., 2000; Blanksby et al., 2002; Lyttle \& Benjanuvatra, 2005). In addition, the swimmers remained the fastest over $10 \mathrm{~m}$ using their preferred technique. Mechanically, this variable encompassed all of the observed from the start signal to the end of the trial.

The results showed that the dive performance variables block time, flight time, and peak horizontal force of the lower limbs directly influenced time to $10 \mathrm{~m}$. It is therefore recommended that coaches use these variables as primary indicators to improve dive start performance during training sessions. When comparing the swimmers' respective block time and flight time for each dive type, no significant difference was found; however, when both these variables were summed, significant differences were revealed for each dive type. Thus, overall swim entry was significantly faster when the swimmers used the conventional method; the time the swimmer spent on the blocks and in the air was reduced when using two hands. Furthermore, the swimmers' flight time and total time results in the current study were similar to those observed in previous dive start literature while using elite subjects (Blanksby et al., 2002; McLean et al., 2000; Allen et al., 1999).

Significant differences were found in peak vertical force of the lower limbs when comparing the two different dive starts; swimmers generated greater vertical force off the block while using the conventional track start. This might reflect the fact that grabbing the block with two hands may produce a larger preload on the force plate than a one-arm grab and might also suggest that the one-handed start allowed unwanted rotation in the body and displacement in the lateral direction. In contrast to horizontal velocity off the blocks, when controlling for covariance, there were no significant differences found in horizontal force or horizontal impulse generated. The swimmers in the current study displayed overall force characteristics, including the horizontal impulse (mean $124.8 \pm 22.6 \mathrm{~N} \cdot \mathrm{s}$ ), similar to those found in previous track start literature (Breed \& McElroy, 2000). The upper- and lower-limb ground reaction force generation was also similar to reports in previous track start literature (Breed \& McElroy, 2000; Breed \& Young, 2003; Kruger et al., 2002; and Lyttle \& Benjanuvatra,
2005). As peak force was achieved during the rear foot push off, it is suggested that the swimmers' dominant leg be placed to the rear of the block. Although it has been suggested by Breed \& McElroy (2000) that the contribution and role of the arms in the track start represented one-third of the total horizontal impulse, this study did not concur: Less than one-third of the total horizontal impulse was produced by the swimmers' arms when using both starting techniques.

In previous studies, increasing flight distance was shown to be a key component of dive performance (Pearson et al., 1998; Breed \& McElroy, 2000). In the current study, swimmers achieved significantly greater flight distance when using the new technique. Although swimmers covered more distance off the block using the new dive style, longer flight distance did not equate to faster overall performance times. This finding may indicate that there is a trade-off between flight distance and horizontal velocity generated at take-off. Hence, in concurrence with Allen et al. (1999), flight distance was not deemed to be an influencing factor of track start dive performance to $10 \mathrm{~m}$.

The results also found that swimmers generated significantly greater horizontal velocity at take-off when using the two-handed track start. The attainment of greater horizontal velocity has been seen as a benefit to overall dive performance as it allows the swimmer to enter the water at a greater speed and thus eliminate some of the loss in speed due to impact with the water.

The current study showed no significant differences in take-off angles, which ranged from $0.7^{\circ}$ to $8.6^{\circ}$ for the track start and from $0^{\circ}$ to $5.4^{\circ}$ for the one-handed track start; previous findings using elite dive starts have shown optimal take-off angles range from $-5^{\circ}$ to $10^{\circ}$ (Lyttle \& Benjanuvatra, 2005).

Irrespective of dive type, the intervention group performed significantly better on time to $10 \mathrm{~m}$. Irrespective of group type, the track start had significantly greater peak vertical force of the lower limbs and takeoff angle than the one-handed start. There was no difference in the variables when dive type and group were combined.

Experimental error margins aside, the results of this preliminary investigation suggest that the four covariate variables (block time, flight time, peak horizontal force of the lower limbs, and vertical velocity) may directly influenced dive performance and consequently are considered most important in the future training of dive starts. Coaches and competitive swimmers should focus on improving leg strength and power to maximize horizontal force of the lower limbs and vertical velocity off the blocks. Future research could investigate the optimum foot placement of the one-handed technique while using higher speed cameras and a longer training intervention.

Significant kinematic and kinetic differences in the track start and one-handed track start were found, suggesting that upper-body alterations associated with the new one-handed method significantly changed the 
biomechanics of the track start. Although swimmers gained greater distance off the blocks, the results indicated that the changes in technique led to a reduction in dive performance over $10 \mathrm{~m}$. The conventional track start was significantly faster over $10 \mathrm{~m}$ and therefore may be seen as a superior start after a short intervention period. Coaches and swimmers should place emphasis on the most significant dive variables found, including the generation of as much peak horizontal force of the lower limbs off the blocks while gaining a favorable take-off angle and optimal amount of vertical velocity to maximize time in the air.

\section{Acknowledgments}

This study was conducted with the continued support of Lee Cogger, Phil Newton, and the University of Portsmouth engineering department, specifically Geoff Moase and Rick Baker. Sincere appreciation is owed to the Royal Navy pool staff and the Portsmouth Northsea swim club head coach and swimmers. Additional testing equipment for the study was supplied by British Swimming and the University of Salford Biomechanics Department.

\section{References}

Allen, D., Miller, M., Pein, R., \& Oyster, C. (1999). A kinetic and kinematic comparison of the grab start and track start in swimming. Research Quarterly in Exercise Science, (Suppl.), A-15 (abstract).

Ayalon, A., Van Gueluwe, B., \& Kanitz, M. (1975). A comparison of four styles of racing start in swimming. In $\mathrm{L}$. Lewillie \& J. Clarys (Eds.), Swimming II, International series of sport science (pp. 233-240). Baltimore: University Park Press.

Blanksby, B., Nicholson, L., \& Elliott, B. (2002). Biomechanical Analysis of the Grab, Track, and Handle Swimming Starts: An Intervention Study. Sports Biomechanics, 1(1), $11-24$.

Blitvich, J.D., McElroy, G.K., Blanksby, B.A., Clothier, P.J., $\&$ Pearson, C.T. (2000). Dive depth and water depth in competitive swim starts. Journal of Swimming Research, $14,33-39$.

Bowers, J., \& Cavanagh, P. (1975). A biomechanical comparison of the grab and conventional sprint starts in swimming. In L. Lewillie \& J. Clarys (Eds.), Swimming II, International series of sport science (pp. 225-232). Baltimore: University Park Press.

Breed, R., \& Young, W. (2003). The effect of a resistance training programme on the grab, track and swing starts in swimming. Journal of Sports Sciences, 21, 213-220.

Breed, R., \& McElroy, G. (2000). A biomechanical comparison of the grab, swing and track starts in swimming. Journal of Human Movement Studies, 39, 277-293.

Carlile, F. (1963). Forbes Carlile on swimming. London: Pelham books.

Cavanagh, P., Palmgren, J., \& Kerr, B. (1975). A device to measure forces at the hands during the grab start. In L. Lewillie \& J. Clarys (Eds.), Swimming II, International series of sport science (pp. 43-50). Baltimore: University Park Press.
Colwin, C. (1969). Cecil Colwin on Swimming. Slough: Pelham Books.

Cossor, J., Blanksby, B., \& Elliot, B. (1999). The influence of plyometric training on the freestyle tumble turn. Journal of Science and Medicine in Sport, 2(2), 106-116.

Costill, D.L., Maglischo, E.W., \& Richardson, A.B. (1992). Handbook of Sports Medicine and Science in Swimming. London: Blackwell Science Ltd.

Counsilman, J. (1985). The Science of Swimming. Slough: Pelham books.

Counsilman, J., Counsilman, B., Nomura, T., \& Endo, M. (1988). Three types of grab starts for competitive swimming. In Swimming Science $V-5$ th International Symposium of Biomechanics and Medicine in Swimming (pp. 81-91). Champaign: Human Kinetics.

Guimaraes, A.C.S., \& Hay, J.G. (1985). A mechanical analysis of the grab starting technique in swimming. International Journal of Sport Biomechanics, 1, 25-35.

Havriluk, R. (1983). A criterion measure for the swimming start. In P. Hollander, P. Huijing, \& G. de Groot (Eds.) Biomechanics and Medicine in Swimming, P Proceeding of the Fourth International Symposium of Biomechanics in Swimming (pp.89-95). Baltimore: University Park Press.

Hopkins, W., Hawley, J., \& Burke, L. (1999). Design and analysis of research on sport performance enhancement. Medicine and Science in Sports and Exercise, 31(3), 472-485.

Kruger, T. Wick., D., Hohmann, A., El-Bahrawi, M. \& Koth, A. (2002). Biomechanics of the grab and track start technique [Electronic version]. In Biomechanics and Medicine in Swimming IX. Proceeding of the IX International Symposium on Biomechanics and Medicine in Swimming. (pp.219- 223).University of Saint-Etienne, France. Retrieved May 11, 2005, from http://www.uni-potsdam. de/u/ABTUBW/for_Line_A2.htm

Lyttle, A., \& Benjanuvatra, N. (2005). Start right: A biomechanical review of dive start performance [Electronic version]. Retrieved May 11, 2005, from Coaches Information Website: http://www.coachesinfo.com/category/ swimming/321/

Maglischo, E. (2003). Swimming Fastest. (revised ed. of Swimming Even Faster). Champaign, IL: Human Kinetics.

McLean, S.P., Holthe, M.J., Vint, P.F., Beckett, K.D., \& Hinrichs, R. (2000). Addition of an approach to a swimming relay start. Journal of Applied Biomechanics, 16, 342-355.

Nelson, R., \& Pike, N. (1978). Analysis and comparison of swimming starts and strokes. In B. Eriksson, B. Furberg, R. Nelson, \& C. Morehouse (Eds.), Swimming Medicine $I V$, International series of sport science, Volume 6, Proceedings of the Fourth International Congress on Swimming Medicine (pp. 347-359). Baltimore: University Park Press.

Pearson, C., McElroy, J., Blitvich, J., Subic, A., \& Blanksby, A. (1998). A comparison of the swimming start using traditional and modified starting blocks. Journal of Human Movement Studies, 34, 49-66.

Shierman, G. (1979). The grab and conventional swimming starts: a force analysis. Journal of Sports, Medicine, and Physical Fitness, 19(2), 171-180. 
Smith, D., Norris, S., \& Hogg, J. (2002). Performance evaluation of swimmers: scientific tools. Sports Medicine (Auckland, N.Z.), 32(9), 539-554.

Stevenson, J.R., \& Moorehouse, C.A. (1979). Influence of starting block angle on the grab start in competitive swimming. In Swimming III: Proceedings of the Third International Symposium of Biomechanics in Swimming (pp. 207-214), Edmonton, Alberta: University of Alberta.

Thayer, A., \& Hay, J. (1984). Motivating start and turn improvement. Swimming Technique, 20(4), 17-20.
Welcher, R.L., Hinrichs, R.N., \& George, T.R. (1999). An analysis of velocity and time characteristics of three starts in competitive swimming. XVIIth ISB Congress, $33(10), 400$.

Zatsiorsky, V., Bulgakova, N., \& Chaplinsky, N. (1979). Biomechanical analysis of starting techniques in swimming. In Swimming III: Proceedings of the Third I International Symposium of Biomechanics in Swimming (pp. 199-206), Edmonton, Alberta: University of Alberta. 